\title{
Peran Guru dalam Pengambangan Multimedia Interaktif (Suatu Tinjauan Kompetensi Guru dan Kaitannya dengan Media Interaktif)
}

\author{
Huriyah Padhilah Anasti \\ Program Magister Fakultas Bahasa dan Seni, Universitas Negeri Padang \\ 3030huri@gmail.com
}

Media pembelajaran merupakan bagian terpenting dalam suatu proses pembelajaran. Media pembelajaran merupakan suatu alat yang digunakan untuk membantu proses belajar mengajar. Tujuan penggunaan media pembelajaran adalah untuk merangsang pola pembelajaran agar dapat mencapai keberhasilan pembelajaran dan mencapai tujuan yang diinginkan (Setiawan et al., 2021: 47). Media pembelajaran yang digunakan harus bervariasi seiring dengan pesatnya perkembangan zaman (Novelti et al., 2018: 112). Pada masa sekarang ini kita sudah sampai pada pendidikan paradigma pembelajaran abad 21 yang menuntut para pendidik agar harus mampu menciptakan inovasi-inovasi terkini dalam proses pembelajaran guna meningkatkan prestasi belajar (Mulyadi et al., 2020: 1). Salah satu inovasi media pembelajaran yang dibutuhkan pada masa sekarang ini mengingat pandemi covid-19 adalah media berbasis teknologi. Media dikembangkan agar sesuai dengan kebutuhan siswa saat ini dengan memanfaatkan perangkat teknologi. Banyak lingkungan pendidikan formal pada masa sekarang mengharuskan pembelajaran dilakukan secara online. Oleh karena itu pembelajaran harus dikembangkan agar dapat digunakan oleh siswa dalam konteks pembelajaran digital atau pembelajaran online (Atmazaki et al., 2021: 3). Selain itu media pembelajaran berbasis teknologi bagi siswa dapat menumbuhkan sikap positif mereka terhadap materi serta keberlangsungan proses pembelajaran (Mulyadi et al., 2020: 2).

Wujud dari media pembelajaran berbasis teknologi yang sesuai digunakan pada masa pandemi covid-19 ini adalah salah satunya media pembelajaran multimedia interaktif. Terentyeva (dalam Ramadhan, 2020: 2) menyatakan bahwa pemanfaatan multimedia memungkinkan pembelajaran berlangsung di kelas maupun di rumah yang terkomputerisasi. Sehingga dimungkinkan juga untuk diadaptasi dalam pembelajaran jarak jauh. Zamzam (2021: 2) mendefinisikan multimedia interaktif sebagai media pembelajaran yang menggabungkan berbagai media berupa gambar, teks, audio atau animasi yang bersifat interaktif dengan tujuan memberikan 
informasi. Rachmadtullah dan Sumantri serta Ramadhani dan Muhtadi (dalam Nuraini et al., 2021: 34) menyatakan bahwa multimedia interaktif digunakan dengan memanfaatkan media komputer sebagai penunjang dalam proses pembelajaran, atau juga dapat memanfaatkan smartphone atau android. Yuong (dalam Mulyadi et al., 2020:2) menyatakan bahwa pemanfaatan multimedia dalam pembelajaran memberikan kesempatan terutama kepada siswa dan guru untuk mengembangkan teknik pembelajaran yang sesuai dengan tujuan untuk mencapai hasil pembelajaran yang maksimal. Sedangkan menurut Pranata (dalam Zamzam, 2021: 2) memanfaatkan multimedia interaktif sebagai alat bantu instruksional dapat membentuk kemandirian peserta didik. Sejalan dengan pendapat tersebut, Munir (dalam Apriati et al., 2021: 14) menyatakan beberapa alasan pentingnya pembelajaran menggunakan multimedia interaktif adalah: (a) pesan dalam materi yang disampaikan terasa lebih nyata, (b) media merangsang berbagai indera sehingga antara indera terjadi suatu interaksi, (c) visualisasi dalam bentuk teks, gambar, audio, video, maupun animasi bagi siswa akan lebih mudah diingat dan ditangkap, (d) pembelajaran dengan menggunakan teknologi seluler menjadikan pembelajaran lebih praktis dan terkendali, dan (e) waktu, biaya, dan energi lebih hemat.

Dalam pembelajaran bahasa Indonesia, media pembelajaran berupa multimedia interaktif sangat diperlu dalam pembelajaran jarak jauh (online) pada masa ini. Hal ini mengingat bahwa pembelajaran bahasa Indonesia mencakup 4 aspek keterampilan berbahasa yang harus dikuasai oleh siswa. Kharade \& Peese (dalam Ramadhan et al., 2018: 195) menyatakan bahwa pembelajaran bahasa merupakan proses yang kompleks yang mencakup berbagai dimensi berupa dimensi intelektual, sosial dan emosional. Dapat dikatakan bahwa mengajar bahasa baik Indonesia maupun bahasa apa pun adalah kegiatan multidimensi, sehingga pembelajaran bahasa yang berlangsung harus mampu dirancang oleh guru agar kegiatan multidimensi dapat terwujud. Salah satu arakteristik yang dimiliki oleh media pembelajaran multimedia interaktif sangat sesuai dengan pembelajaran bahasa. Andajani serta Heinich et al., (dalam Apriati et al., 2021: 16) menyatakan multimedia interaktif tidak hanya sebatas memperlihatkan media atau objek kepada siswa, tetapi siswa juga dituntut untuk berinteraksi selama pembelajaran berlangsung. Pemanfataan media berbasis multimedia interaktif bagi pembelajaran bahasa telah dibuktikan dalam suatu penelitian oleh Mulyadi et al. (2018) yang memperoleh hasil bahwa pembelajaran bahasa Indonesia dengan menggunakan e-modul berbasis multimedia interaktif yang berlangsung pada mahasiswa IAIN 
Bukittinggi sangat efektif digunakan. E-modul multimedia interaktif juga dapat dan mampu meningkatkan prestasi belajar dan minat belajar.

Pengembangan dan pemanfaatan media pembelajaran berbasis multimedia interaktif tentunya tidak dapat dipisahkan dengan kompetensi yang dimiliki oleh guru. Hal ini mengingat bahwa guru berperan dalam segala bentuk proses pembelajaran. Menurut Hoydalsvik (dalam Indriyani et al., 2019: 110) guru merupakan aktor dalam perubahan, guru mengambil bagian dalam proses pengembangan kebijakan. Pendapat lain yang mempertegas hal tersebut menyatakan kompetensi.yang.dimiliki oleh guru memberikan gambaran terhadap kemampuannya dalam menjalankan tugasnya dengan profesional atau sebaliknya (Linda dan Ngazizah, 2021: 59). Guru yang profesional merupakan kunci dalam melaksanakan pendidikan yang berkualitas di sekolah (Lahami, 2021: 14). Guru profesional harus mampu beradaptasi dengan perkembangan teknologi yang tercermin dari kemampuannya dalam memanfaatkan media dan sumber belajar digital (Agusrida et al., 2020: 370-371). Oleh karena itu sangat diharapkan adanya guru yang profesional dalam pengembangan media pembelajaran berbasis multimedia interaktif. Supriyanto (dalam Supriatna, 2021: 215) menyatakan bahwa kompetensi guru mengembangkan media pembelajaran dengan berbasis teknologi informasi dan komunikasi sangat penting untuk terlaksananya pembelajaran online secara efektif. Tetapi sangat disayangkan bahwa pada kenyataannya menurut Levitskaya \& Seliverstova (dalam Supriatna, 2021: 215) bahwa kompetensi guru dalam memanfaatkan teknologi informasi dan komunikasi dalam pembelajaran belum memadai, masih banyak guru yang menggunakan teknologi secara sederhana dan cenderung melaksanakan pembelajaran secara tradisional. Berdasarkan hal tersebut dapat disimpulkan bahwa kompetensi dan profesionalitas guru dalam pengembangan media pembelajaran berbasis multimedia interaktif harus ditingkatkan lagi, hal ini mengingat bahwa guru sangat berperan penting dalam pengembangan media pembelajaran tersebut.

\section{Sumber Rujukan:}

Agusrida, Atmazaki, Ramadhan, S., dan Ermanto. (2020). Effectiveness of Online Scientific Publication Training Approach for Teacher's Professional Competence Development at Religious Training Centre in Padang. Atlantis Press, 370-375. 
Apriati, L., Mulawarman, W. G., dan Ilyas, M. (2021). Pengembangan Bahan Ajar Menyimak Berbasis Multimedia Interaktif pada Pembelajaran Tematik dengan Tema "Indahnya kebersamaan" untuk Siswa Kelas VI Sekolah Dasar. Diglosia, 4(1), 13-22.

Atmazaki, Ramadhan, S., Indriyani, V., dan Nabila, J. (2021). Dialogic-Interactive Media Design for Language Learning to Improve Speaking Activites and Skills. IOP Publishing, 1-9.

Indriyani, V., Zaim, M., Atmazaki, dan Ramadhan, S. (2019). Literasi Baca Tulis dan Inovasi Kurikulum Bahasa. Kembara: Jurnal Keilmuan Bahasa, 5(1), 108-118.

Lahami, M. A. G. (2021). Pengaruh Workshop Media Pembelajaran terhadap Peningkatan Kompetensi Guru dalam Mengembangkan Media Pembelajaran. JETCLC: Journal of Educational Technology, Curriculum, Learning, and Communication, 1(1), 13-21.

Linda, R. F. C., dan Ngazizah, N. (2021). Kompetensi Guru terhadap Pembelajaran Daring pada Masa Pandemi Covid-19. At-Thullab: Jurnal Pendidikan Guru Madrasah Ibtidaiyah, 5(1), 57-74.

Mulyadi, Atmazaki, Ramadhan, S., dan Agustina. (2018). The Development of Interactive Multimedia E-Module on Indonesia Language Course. Atlantis Press, 291-295.

Mulyadi, Ramadhan, S., Atmazaki, dan Agustina. (2020). The Development of E-Modules Based on Adobe Flash for Indonesia Subjects at IAIN Bukittinggi. IOP Publishing, 1-8.

Novelti, Ramadhan, S., Ermanto, dan Agustina. (2018). Developing in Instructional Model Assisted Audio Visual Media. Atlantis Press, 111-116.

Nuraini, M. F. (2021). Pengembangan Multimedia Interaktif Materi Perubahan Wujud Benda Bagi Siswa Sekolah Dasar. JKTP: Jurnal Kajian Teknologi Pendidikan, 4(1), 33-40.

Ramadhan, S., Asri, Y., dan Indriyani, V. (2018). Learning Module Design Writing Argumentative Text Based Problem-Based Learning. Atlantis Press, 194-200.

Ramadhan, S., Atmazaki, Sukma, E., dan Indriyani, V. (2020). Multimedia with Social Learning Nerwork (SNL): As Learning Innovation in the 4.0 Industrial Era. IOP Publishing, 1-9.

Setiawan, B., Pramulia, P., Kusmaharti, D., Juniarso, T., dan Wardani, I. S. (2021). Peningkatan Kompetensi Guru Sekolah Dasar dalam Pengembangan Media Pembelajaran Daring SDN Morgorejo 1 Kota Surabaya. Manggali, 1(1), 46-57.

Supriatna, U. (2021). Kompetensi Guru Memanfaatkan Teknologi Informasi dan Komunikasi dalam Mengembangkan Media Pembelajaran Online. Edumaspul, 5(1), 214-221.

Zamzam, K. F. (2021). Pengembangan Multimedia Interaktif Geometri Transformasi Berbasis Discovery Learning dengan Pendekatan Kontekstual. JPIn: Jurnal Pendidikan Indonesia, $4(1), 1-9$. 